\title{
Patrimônio Genético Brasileiro: Protegê-lo ou Aproveitá-lo Comercialmente?
}

As recentes ações do IBAMA, como parte da Operação Novos Rumos (iniciada em 2010), notificando instituições de pesquisas, empresas dos segmentos farmacêutico, cosmético e agropecuário, acusadas de biopirataria e investigadas pela suposta coleta ilegal de produtos da biodiversidade brasileira, têm levado as empresas do setor à paralisação de suas atividades dessa área.

Essa paralisação é o resultado da incerteza jurídica causada pelas inúmeras falhas e omissões encontradas na Medida Provisória-MP N ${ }^{\circ}$ 2.186-16, de 23 de agosto de 2001, que dispõe sobre o acesso ao patrimônio genético, a proteção e o acesso ao conhecimento tradicional associado, a repartição de benefícios e o acesso à tecnologia e transferência de tecnologia para a conservação e utilização do patrimônio genético nacional, agravada pelo endurecimento da fiscalização, com a aplicação de pesadas multas e sanções sobre empresas, universidades e centros de pesquisa.

Na mesma MP também foi criado o Conselho de Gestão do Patrimônio Genético (CGEN) com caráter deliberativo e normativo e que tem, entre suas competências e atribuições, a coordenação da implementação de políticas para a gestão do patrimônio genético, o estabelecimento de normas técnicas, dos critérios para as autorizações de acesso e de remessa; das diretrizes para elaboração do Contrato de Utilização do Patrimônio Genético e de Repartição de Benefícios; dos critérios para a criação de base de dados para o registro de informação sobre conhecimento tradicional associado, o acompanhamento das atividades de acesso e de remessa de amostra de componente do patrimônio genético e de acesso a conhecimento tradicional associado, a deliberação sobre autorização de acesso e de remessa de amostra de componente do patrimônio genético, a autorização do acesso a conhecimento tradicional associado, o credenciamento de instituições públicas nacionais para serem fiéis depositárias de amostra de componente do patrimônio genético, dar anuência aos Contratos de Utilização do Patrimônio Genético e de Repartição de Benefícios, a promoção de debates e consultas públicas sobre os temas de que trata a MP, além de dezenas de outras atribuições.

Para dar conta deste emaranhado de atribuições e atividades, o CGEN é formado por 19 órgãos e entidades da Administração Pública Federal com direito a voto como os Ministérios do Meio Ambiente, Ciência e Tecnologia, Saúde, Justiça, Agricultura, Defesa, Cultura; Relações Exteriores, Indústria e Comércio, o IBAMA, o Jardim
Botânico do Rio de Janeiro, o CNPq, o Instituto Nacional de Pesquisa da Amazônia, o Museu Emílio Goeldi, a Embrapa, a FIOCRUZ, a Funai, e o INPI, além de contar com convidados em suas reuniões deliberativas com direito a apenas voz, como a Fundação Cultural Palmares, a SBPC, a Associação Brasileira de Organizações Não Governamentais, a Associação Brasileira das Empresas de Biotecnologia, o Conselho Empresarial Brasileiro para o Desenvolvimento Sustentável, a Comissão Nacional de Articulação das Comunidades Negras Rurais Quilombolas, o Conselho Nacional de Seringueiros, a Coordenação das Organizações Indígenas da Amazônia, entre outros.

Criou-se, assim, um monstro burocrático incapaz de tomar qualquer decisão em um tempo razoável. Como consequência, existem pedidos e processos enviados ao CGEN esperando decisão há mais de quatro anos, sem nenhuma expectativa de se obter alguma resposta.

O objetivo da MP era impedir que empresas multinacionais, entidades e indivíduos, inspirados pelo conhecimento tradicional e motivados por interesses econômicos escusos roubassem moléculas da fauna e da flora do País para transformá-las em medicamentos e cosméticos no exterior.

É claro que essa situação ocorreu no passado distante (lembremo-nos do caso da seringueira, de biopirataria para fora, e do café e do açúcar, de biopirataria para dentro), em passado recente (da mesma forma, lembremo-nos do caso Bioamazônia-Novartis) e é evidente que alguma posição deveria ser tomada a respeito, ainda mais sendo o país signatário da Convenção sobre Diversidade Biológica.

O problema é que a realidade e a diversidade das situações de acesso ao patrimônio genético no país são muitíssimo mais variadas e complexas do que prevê a MP. Lembremo-nos que nossa herança cultural sempre nos fez utilizar os nossos recursos genéticos naturais em aplicações tão diversas como alimentos, remédios, cosméticos, artefatos diversos e muitos outros usos. Ao olharmos em volta, veremos que da muqueca capixaba à tigela de açaí na loja de sucos da esquina, estamos utilizando recursos oriundos da biodiversidade brasileira. E a banana? É brasileira ou não? Devemos solicitar autorização ao CGEN para utilizá-la? E a maçã? É européia, por certo, mas e a variedade desenvolvida pela Embrapa para as condições brasileiras? E a soja tropical, uma planta chinesa que foi melhorada e adaptada ao solo do cerrado, que rende bilhões de dólares ao país? É nossa ou não é? E a cana, em situação idêntica? 
O que a MP entende como "patrimônio genético"? A definição, encontrada no artigo $7^{\circ}$, inciso I, diz que patrimônio genético compreende "toda a informação de origem genética, contida em amostras do todo ou de parte de espécime vegetal, fúngico, microbiano ou animal, na forma de moléculas e substâncias provenientes do metabolismo destes seres vivos e de extratos obtidos destes organismos vivos ou mortos, encontrados em condições in situ, inclusive domesticados, ou mantidos em coleções ex situ, desde que coletados em condições in situ no território nacional, na plataforma continental ou na zona econômica exclusiva". Em outras palavras, pela MP, o açaí e o guaraná, assim como banana, maçã, uva, soja, e cana de açúcar poderiam ser considerados como parte do nosso patrimônio genético.

É claro que a MP não trata do acesso direto ao patrimônio representado pelo saborear de uma tigela de açaí ou de comer uma banana. Afinal, o que é considerado, então, o tal "acesso ao patrimônio genético"?

Ainda de acordo com as definições encontradas no artigo $7^{\circ}$, o inciso IV nos informa que o acesso ao patrimônio genético trata da "obtenção de amostra de componente do patrimônio genético para fins de pesquisa científica, desenvolvimento tecnológico ou bioprospeç̧ão, visando a sua aplicação industrial ou de outra natureza".

Ainda temos outro tema, que é o acesso ao "conhecimento tradicional associado". Mais uma vez, consultando o artigo $7^{\circ}$, descobrimos que se trata de "informação ou prática individual ou coletiva de comunidade indígena ou de comunidade local, com valor real ou potencial, associada ao patrimônio genético", e que o "acesso ao conhecimento tradicional associado" trata da "obtenção de informação sobre conhecimento ou prática individual ou coletiva, associada ao patrimônio genético, de comunidade indígena ou de comunidade local, para fins de pesquisa científica, desenvolvimento tecnológico ou bioprospecção, visando sua aplicação industrial ou de outra natureza".

Assim, chega-se à conclusão que a MP pretende regular o acesso ao patrimônio genético e ao conhecimento tradicional associado quando existe alguma possibilidade de aplicação industrial do material derivado do patrimônio genético brasileiro.

Não se sabe o que a MP entende o que possa ser considerado "de outra natureza", como consta no texto.

A complexidade do tema mostra que, entre o claro e o escuro, existe uma enorme zona cinzenta, na qual se encontram milhares de empresas, em dezenas de setores, em centenas de situações não previstas pela MP e muito, muito longe do que poderia ser considerado biopirataria. Nesse cenário, infinitamente mais complexo do que aquele imaginado pelos autores da MP, aparecem então diversas situações de desigualdade no trato da questão, que incluem a ampla desinformação dos setores potencialmente atingidos pela MP (que nunca ouviram falar dessa MP e não se acham incluídos entre empresas que acessam o patrimônio genético brasileiro - seja lá o que for isso), passa pela ação dos lobbies, que protegem determinados setores e atingem outros setores com mais consciência e visibilidade.

Dentre as empresas com consciência e visibilidade que foram vítimas dessa desigualdade de tratamento estão, por exemplo, algumas indústrias cosméticas expressivas que, desde a emissão da MP 2.186, já buscavam regularizar suas atividades de pesquisa e desenvolvimento com plantas pertencentes ao nosso patrimônio genético. Os impasses criados pela falta de clareza da MP, associados à forte pressão para lançar novos produtos, acabou colocando-as em uma situação de "ilegalidade exposta", o que acabou resultando na aplicação de pesadas multas a essas empresas - ironicamente, justamente aquelas que buscaram respeitar a MP.

Some-se a isso o fato de o IBAMA - um órgão de governo com função fiscalizatória - ter assento no Conselho (CGEN) e está criado o paradoxo: quem quer se regularizar deve apresentar seu pedido ao CGEN, que tem o IBAMA entre seus componentes, que, ao tomar conhecimento de que determinada indústria quer se regularizar (estando, portanto, irregular até aquele momento), notifica a empresa, aplicando-lhe multas que podem chegar a milhões de reais!!!

A publicação recente de uma nova resolução (RESOLUÇÃO N 35, DE 27 DE ABRIL DE 2011), publicada com o objetivo de "regularizar as atividades de acesso ao patrimônio genético elou ao conhecimento tradicional associado e sua exploração econômica realizadas em desacordo com a Medida Provisória $N^{\circ}$ 2.186-16" já prepara a armadilha e oficializa o paradoxo, pois o artigo $9^{\circ}$ diz claramente que "nos casos de que trata esta Resolução, envolvendo a exploração econômica de produto ou processo desenvolvido a partir de amostra de componente de patrimônio genético ou de conhecimento tradicional associado, em desacordo com as normas vigentes, o Conselho de Gestão do Patrimônio Genético comunicará ao órgão da Advocacia-Geral da União-AGU para conhecimento e providências".

Simplificando: Se você quiser se ajustar à MP será multado EM 20\% DO SEU FATURAMENTO BRUTO, entre outras penalidades previstas em lei.

Assim, a combinação da falta de clareza da própria MP com os problemas operacionais do Conselho e a ação repressiva desencadeada por um de seus componentes, terminaram por levar a chamada "economia da biodiversidade brasileira" à paralisação. 
Como já é do conhecimento dos biólogos e dos economistas, sistemas organizados, como seres vivos (de bactérias ao Homo sapiens) e empresas, para manterem-se viáveis, devem se adaptar às mudanças do seu meio. Isso não é diferente no setor cosmético.

As empresas então simplesmente abandonam os ambientes onde há incertezas capazes de afetá-las e se deslocam para ambientes mais seguros. No caso, dada a necessidade permanente de inovação, com novos lançamentos a cada mês, simplesmente desloca-se o esforço de pesquisa e desenvolvimento para o uso de plantas importadas, fora da abrangência da MP.

O resultado, visível em alguns setores cuja necessidade de inovação é constante e acelerada, tais como o de cosméticos, é que as empresas estão simplesmente abandonando todos os projetos atualmente em curso que envolvam o uso de qualquer produto que seja entendido como sendo proveniente da Biodiversidade Brasileira.

Não nos esqueçamos também que o país não é o único detentor de áreas na Amazônia: Guiana Francesa, Suriname, Guiana, Bolívia, Venezuela, Peru, Colômbia também possuem parte dos seus territórios na chamada região amazônica. Já existem, por exemplo, fornecedores franceses de extrato de guaraná e fabricantes espanhóis de extrato de açaí.

Outra alternativa que essas indústrias já veem com bons olhos é o uso de plantas que não fazem parte da biodiversidade brasileira nem são obtidas aqui (para escapar da extensão da interpretação do que seria "patrimônio genético brasileiro", definida na MP). Os profissionais de marketing das empresas farão o serviço de reposicionamento e assim, rapidamente, veremos novos lançamentos de produtos utilizando uva chilena no lugar do açaí e azeite de oliva italiano no lugar do óleo de castanhado-Pará. Óleo de Argan do Marrocos e manteiga de Karité de Gana ou de Burkina Faso na África também são opções conhecidas das indústrias cosméticas brasileiras e que não implicam em registros ou autorização junto ao CGEN, nem configuram acesso ilegal ao patrimônio genético brasileiro.

Em resumo: a indústria brasileira se adaptará para sobreviver e, no final das contas, as vítimas inocentes serão o ribeirinho que colhe açaí na Ilha de Marajó, o seringueiro que coleta castanha-do-Pará na floresta amazônica, o sertanejo de Serra Talhada, que vende umbu e pitomba e o pescador que colhe algas marinhas na costa do Ceará. O mercado para seus produtos vai diminuir ou nunca será plenamente desenvolvido. São eles os que mais sofrerão.

O problema, evidentemente, não é a necessidade ou não de uma norma legal a respeito. A participação ativa do país, tanto como sede da Conferência Rio-92, quanto como signatário da Convenção da Diversidade Biológica (ratificada pelo decreto $\mathrm{N}^{\circ} 2.519$ de 16 de março de 1998) e como defensor da conservação da biodiversidade, o seu uso sustentável e da justa repartição dos benefícios provenientes do uso econômico dos recursos genéticos é exemplar e fundamental para a preservação das nossas riquezas.

O problema é a falta de clareza nos critérios, a lentidão das decisões e a falta de segurança legal. Medidas provisórias são instrumentos legais imperfeitos, até porque não foram submetidos à avaliação dos representantes da sociedade, no caso o Congresso Nacional, e a MP 2.186 não foge à regra.

Urge definir um marco legal que faça sentido, com regras claras e sensatas, que criem um ambiente de tranqüilidade e segurança para os atores envolvidos e viabilizem a criação de valor e o aproveitamento econômico, justo e sustentável dos recursos genéticos do país.

\author{
Daniel Weingart Barreto ${ }^{1}$ \\ ASSESSA Indústria, Comércio e Exportação Ltda \\ danielbarreto@assessa.com.br
}

1. Rua Cardoso Quintão, 110, 21.381-460 Rio de Janeiro, RJ. 